\title{
THE RISING TEMPERATURE TREND AND ELONGATION OF THE WARM PERIOD IN SUMMER IN THE ALGERIAN SOUTH-WEST, 1951-2010
}

\author{
MILOUD OUBADI ${ }^{1,2}$, AHMED HAMOU', FANTINA TEDIM ${ }^{3}$
}

\begin{abstract}
Several studies indicate that the hot season is lengthening at the expense of the intermediate seasons, and extreme events are becoming more intense and spread out over time. What is the situation in a climate described as very hot? This work aims to examine the evolution of minimum and maximum temperatures in the hot period from June to September during 19512010 in the Bechar region, which is classified among the hottest in the world and located in the south-west of Algeria. This study will also focus on the extending of the warm period (the period between the first and the last recording of an extremely hot day). The results showed an evolution of maximum and minimum temperatures, leading to an upward trend in the mid$1990 \mathrm{~s}$. There was an average increase of $1^{\circ} \mathrm{C}$ at the maximum and $0.9^{\circ} \mathrm{C}$ at the minimum. The warm period experienced a significant expansion attributed to both the earliest and the latest extremely hot day events.
\end{abstract}

Key words: Algeria, Bechar, extremely hot days, elongation, Mann-Kendall, warm period

\section{Introduction}

Climate change has had and will continue to have an impact on temperature and precipitation (Driouech et al. 2020; Boudiaf et al. 2020). As global mean temperature rises, climate-related impacts and risks are increasing rapidly (Hoegh-Guldberg et al. 2019). One prominent example is that global warming has caused a significant change in temperature amplitudes and a shift in seasons, which have been detected in both temperature and phenological indicators (Allstadt et al. 2015; Christidis et al. 2007; Schwartz et al. 2006). The changes in the phase of the four seasons include their lengths expanding and contracting and their onsets drifting. At low latitudes $\left(0-30^{\circ} \mathrm{N}\right)$, the air temperature varies so little throughout the year that the differences in temperature among the four seasons are not noticeable (Santer et al. 2018). Tropical seasons are generally divided into wet and dry seasons according to precipitation. Consequently, based on temperature, the division of the year into four seasons at low latitudes, where the summer is very long and very hot, is not appropriate.
Over the past 60 years, summer has already lengthened by 17 days on average across the world, but under the business-as-usual scenario, winter is projected to last less than 2 months by 2100 (Wang et al. 2021). The seasonal changes can magnify the strain on human life and ecosystems (water resources, bioresources, animals and plants), representing an increased threat to life on the planet. Therefore, it is of interest to understand how the phase and temperature of the seasons change.

Arid regions present a great sensitivity to climate. They are exposed to extreme phenomena, particularly extremely hot days, which are becoming increasingly intense and extended in time and space (Russo et al. 2016; Oueslati et al. 2017; Barbier et al. 2018; Batté et al. 2018).

This study explores the changes and trends in warm-season temperatures and the modifications represented by the expansion in warm-season length resulting from drift in its onset and end. The warm period is defined as the time interval (number of days) between the first and last extremely hot day over south-west Algeria; this constitutes a case study on the Bechar region covering the period 1951-2010.

\footnotetext{
${ }^{1}$ University of Oran 1-Ahmed Ben Bella, Faculty of Exact and Applied Sciences, Laboratory of Environmental Science and Material Studies, Oran, Algeria; e-mail: oubadi@hotmail.fr, ORCID: 0000-0002-0371-352X

${ }^{2}$ Center for Scientific and Technical Research on Arid Regions, Biskra, Algeria

${ }^{3}$ University of Porto, Faculty of Arts and Humanities, Department of Geography, Porto, Portugal
} 


\section{Data and methods}

\section{Study area}

The Wilaya (division) of Bechar is located in the south-western region of Algeria and covers an area of $161.4 \mathrm{~km}^{2}$. It is about $500 \mathrm{~km}$ long from north to south and about $400 \mathrm{~km}$ wide from east to west (Fig. 1). It is characterised by a Saharantype climate - dry and hot in summer and relatively cold, with rare precipitation in winter $(\mathrm{Ou}-$ badi et al. 2020).

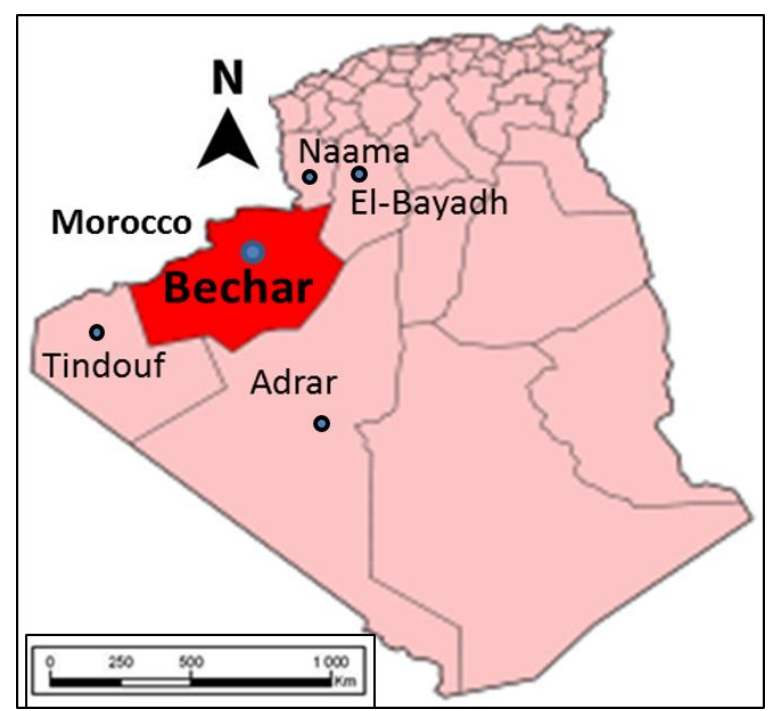

Fig 1. The study area: the Wilaya of Bechar

\section{Methods}

The temperature data used come from the Béchar Meteorological station, which depends on the National Meteorological Office (ONM 2010); these are daily data (Tmax and Tmin) that are homogeneous and uninterrupted for the period 1951-2010. The statistical analysis was carried out first on the average monthly maximum and minimum temperatures during the four hottest months (June, July, August and September).

To study the extension of the warm period, we rely on the dates of extremely hot days recorded from 1951 to 2010. We filter the data to get two series, one representing the date of the first extremely hot day for each year (60 dates), and the second representing the date of the last extremely hot day for each year (60 dates) from 1951 to 2010. Next, we apply the Mann-Kendall test to each series separately.

The nonparametric Mann-Kendall test, based on the correlation between the ranks and order, was used to detect any possible trend in chronological series (Mann 1945; Paturel et al. 1996). For each element Xi or, what amounts to the same thing, for each element $y_{i}$, the number $n_{i}$ of elements $y_{i}$ preceding it $(i>j)$ is calculated such that $y_{i}>y_{j}$ (Mann 1945; Kendall 1975; Some'e et al. 2012).

The test statistic $t$ is then given by equation:

$$
t=\sum_{i=1}^{n} n_{i}
$$

- In the series of temperatures at Bechar from 1951 to 2010, the original values have been replaced by the rank $y_{i}$ (order number), which are given to them when they are in nondecreasing order.

- In the series of the date of the first extremely hot day for each year at Bechar from 1951 to 2010 , the original values have been replaced by the rank $y_{i}$ (order) which is given to the date of the first extremely hot day of the year $i$. Then, they are ordered from the latest to the earliest (from the day of September to the day of June).

- In the series of the date of the last extremely hot day for each year at Bechar from 1951 to 2010 , the original values have been replaced by the rank $y_{i}$ (order), which is given to the date of the last extremely hot day of the year $i$. Then, they are ordered from the earliest to the latest (from a day in June to a day in September).

The statistic average and variance of the test are calculated by:

$$
\begin{gathered}
E(t)=\frac{n(n-1)}{4} \\
\operatorname{Var}(t)=\frac{n(n-1)(2 n+5)}{72}
\end{gathered}
$$

The reduced test statistics are provided by:

$$
\mathrm{u}(\mathrm{t})=\frac{[t-E(t)]}{\sqrt{\operatorname{Var}(t)}}
$$

In particular, if probability $\alpha_{1}$ is determined using a standard normal distribution table such that:

$$
\alpha_{1}=P(|u|>|u(t)|)
$$

the null hypothesis is accepted or rejected at level $\alpha_{0}$, depending on whether we have $\alpha_{1}>\alpha_{0}$ or $\alpha_{1}<\alpha_{0}$. When the values of $u(t)$ are significant, an increasing or decreasing trend can be observed depending on whether $u(t)>0$ or $u(t)<0$ (Sneyers 1975).

As has been stated above, the statistic of the second trend test lends itself better to calculation when, in the case of a significant trend, we wish to locate the start of the phenomenon by means of a sequential analysis.

This comes immediately from the fact that the value of $t$ for the series formed of the first $i$ terms is none other than the sum, 


$$
\mathrm{t}=n_{1}+n_{2}+\cdots n_{i}
$$

that is, the sum (1) stopped at the $i^{\text {th }}$ term. The corresponding value of $u\left(t_{i}\right)$ is obtained by putting $n=i$ in the equation (2) and (3). We may therefore assume that, if the trend is real, its effect is only very recent and it is advisable to await later observations to obtain conformation from them. Note that this principle can be usefully extended to the backward series. In this case, we calculate the number $n^{\prime}{ }_{i}$ of $y_{j}$ terms for each $y_{i}$ term, such that $y_{i}>y_{j}$ with $i<j$, which gives a check on the first calculation, since we have:

$$
n_{i}+n_{i}^{\prime}=y_{i-1}
$$

If we then put:

$$
i^{\prime}=(n+1)-1 \text { and } n_{i}^{\prime}=u\left(t_{i^{\prime}}\right)
$$

which in particular leads to:

$$
u_{i^{\prime}}=u_{n}
$$

In the absence of any trend in the series, the graphical representation of $u_{i}$ and $u_{i}$ in terms of $i$ generally gives curves that overlap several times, whereas in the case of a significant trend, the intersection of these curves enables the start of the phenomenon to be located approximately (Meddi et al. 2005).

We used the threshold approach derived from summer to determine the temperature threshold. This method spatially localises the temperature threshold for heatwaves. It assigns an upper tail threshold $\left(75^{\text {th }}, 80^{\text {th }}, 85^{\text {th }}, 90^{\text {th }}, 95^{\text {th }}\right.$ percentiles $)$ of the PDF constructed from long-term daily summer temperatures (warm season) in each grid (Basagaña et al. 2011; Mazdiyasni et al. 2017; Raei et al. 2018). This approach is conceptual to the PDF-derived threshold but only uses summer (warm season) data and does not consider temporally localized thresholds (Karl et al. 1999; Fischer et al. 2009).

We have chosen to define a day as extremely hot if the sum of its minimum (Tmin) and maximum (Tmax) temperatures is above the $90^{\text {th }}$ percentile (Fig. 2).

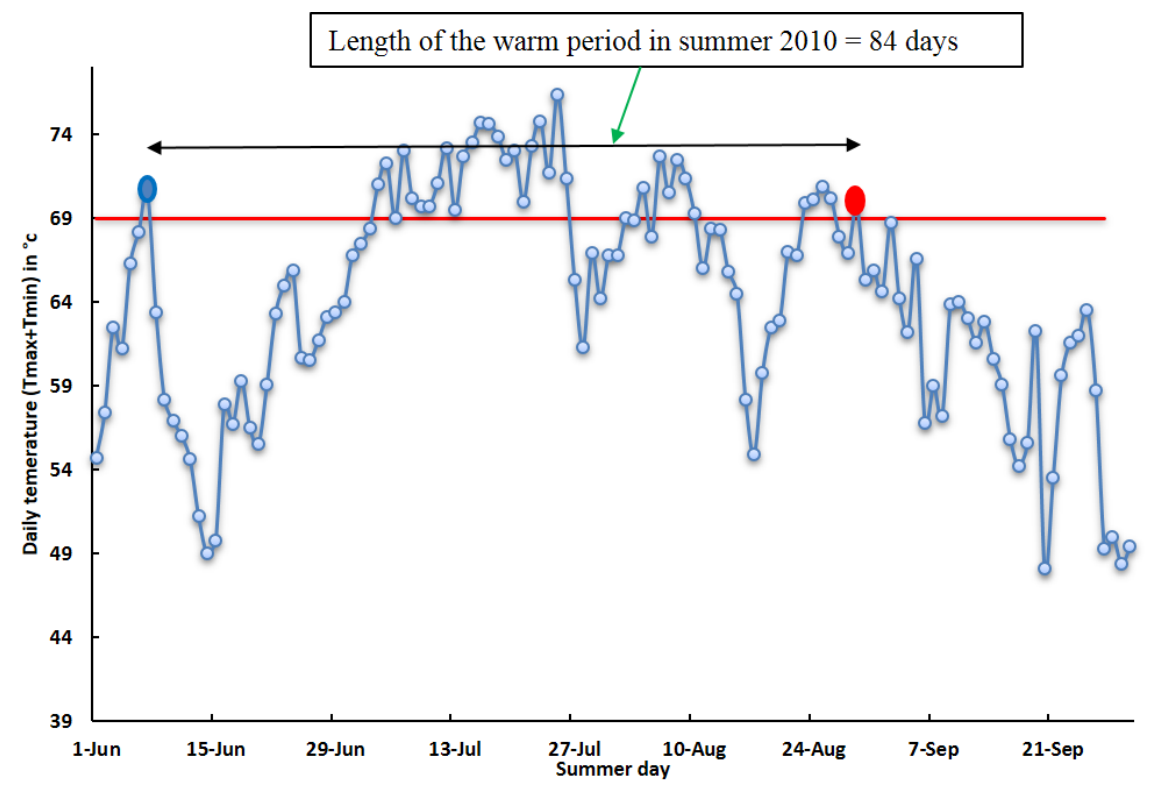

Fig. 2. Illustration of extremely hot summer days in 2010 where (Tmax + Tmin)

is greater than the $90^{\text {th }}$ quantile (red line) calculated over June to September from 1951 to 2010

the big blue (red) point represents the first extremely hot day (the last extremely hot day); the warm period length is the distance between the two points

\section{Results}

\section{Detection of the rupture in the temperature series}

The application of the Mann-Kendall test at a significance level of $5 \%$ identified a break in the temperature series. Identifying these ruptures makes it possible to calculate the increase in the maximum and minimum temperature by the difference between the two periods, after and before the rupture. We detected the existence of a significant upward break in the temperature series $(u(t)$ exceeds the absolute value of the critical value at the 0.05 level, which is 1.96) (Table 1). These 
breaks occurred around 1994 for the series of maximum temperatures and 1993 for the series of minimum temperatures, causing an increase following the jumps of $1^{\circ} \mathrm{C}$ in the maxima and $0.9^{\circ} \mathrm{C}$ in the minima recorded between the periods after and before breaks (Figs. 3, 4).
On the other hand, the linear regression between temperature and time used to quantitatively describe the possibility of a linear decreasing or increasing trend in the time series confirms that the temperatures at the Bechar station have undergone an average increase of $0.02^{\circ} \mathrm{C} /$ year.

Table 1

Mann-Kendall test, temperature evolution, break point years in the study period 1951-2010

\begin{tabular}{|c|c|c|c|c|c|c|}
\hline$T$ & $U(t)$ & $\begin{array}{c}\text { Significance } \\
\text { level }\end{array}$ & Break point year & $\begin{array}{c}\text { Average be- } \\
\text { fore break } \\
\left({ }^{\circ} \mathrm{C}\right)\end{array}$ & $\begin{array}{c}\text { Average after } \\
\text { break }\left({ }^{\circ} \mathrm{C}\right)\end{array}$ & $\begin{array}{c}\text { Change } \\
\left({ }^{\circ} \mathrm{C}\right)\end{array}$ \\
\hline Tmax & 3 & 1.96 & 1994 & 37.1 & 38.1 & 1.0 \\
\hline Tmin & 3.5 & 1.96 & 1993 & 24.3 & 25.2 & 0.9 \\
\hline
\end{tabular}

\section{The onset of the extremely hot days period}

The extremely hot days occurrence date was recorded during the reporting period. When applying the Mann-Kendall test at a significance level of $5 \%$, we noticed a clear positive tendency (Table 2) towards an early appearance of extremely hot days (Fig. 5). At the beginning of the series (before the break around 1999) the occurrence of the first extremely hot days was around the $4^{\text {th }}$ of July.
However, this happened earlier in the second period (after the break). It was around the $16^{\text {th }}$ of June, which means an average of 18 days earlier than in the first period.

The linear regression between the onset of extremely hot summer days and the time (year) shows that the beginning of the extremely hot days moves towards the beginning of summer at an average of 0.4 days/year.

Table 2

Mann-Kendall test, trend in extremely hot days, break years at the year scale for the study period 1951-2010

\begin{tabular}{|l|c|c|c|c|c|c|}
\cline { 2 - 7 } \multicolumn{1}{c|}{} & $U(t)$ & $\begin{array}{c}\text { Significance } \\
\text { level }\end{array}$ & $\begin{array}{c}\text { Year of } \\
\text { break point }\end{array}$ & $\begin{array}{c}\text { Average date } \\
\text { before break }\end{array}$ & $\begin{array}{c}\text { Average date } \\
\text { after break }\end{array}$ & $\begin{array}{c}\text { Drift } \\
\text { (days) }\end{array}$ \\
\hline $\begin{array}{l}\text { Onset of warm } \\
\text { period }\end{array}$ & 4.7 & 1.96 & 1999 & 04-Jul & 16-June & 18 \\
\hline $\begin{array}{l}\text { End of warm pe- } \\
\text { riod }\end{array}$ & 7.2 & 1.96 & 1981 & 08-Aug & 22-Aug & 14 \\
\hline
\end{tabular}

\section{The end of the extremely hot days period}

The Mann-Kendall test confirms that the break point in the series of the last extremely hot day occurred in the year 1981. This positive trend is significant at the 0.05 significance level (Table 2 ). The average end of the warm period during the first period (before the break) was the $8^{\text {th }}$ of August. It moved to the $22^{\text {nd }}$ of August during the second period (after the break). It is thus two weeks later. The linear regression between the extremely hot days end date and the time (year) shows an average delay of 0.4 days/year (Fig. 6).

After 1981, the warm period lengthened by an average of 14 days (due to the drift in the end of extremely hot days) to reach 49 days in length until 1999, when a new drift in the beginning of extremely hot days began. After 1999, the length of the extremely hot days period reached 67 days on average (Fig. 7). 


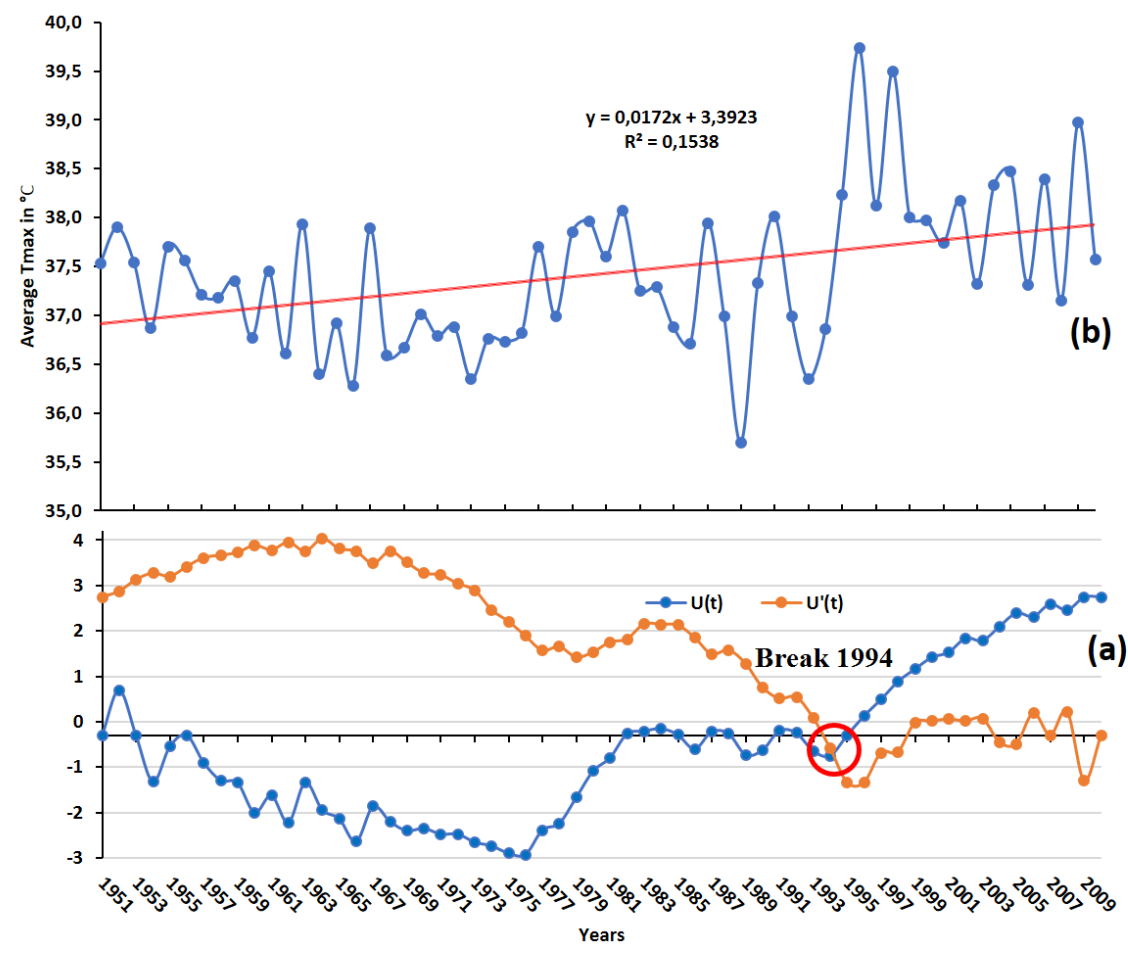

Fig 3. The mean annual maximum temperature (Tmax) trend averaged over June to September of the Bechar station (1951-2010)

(a) - graphic of the series $u(t)$ and the backward series $u^{\prime}(t)$ of the Mann-Kendall statistic test with significant trends for the study period; (b) - the evolution of the maximum temperatures with time

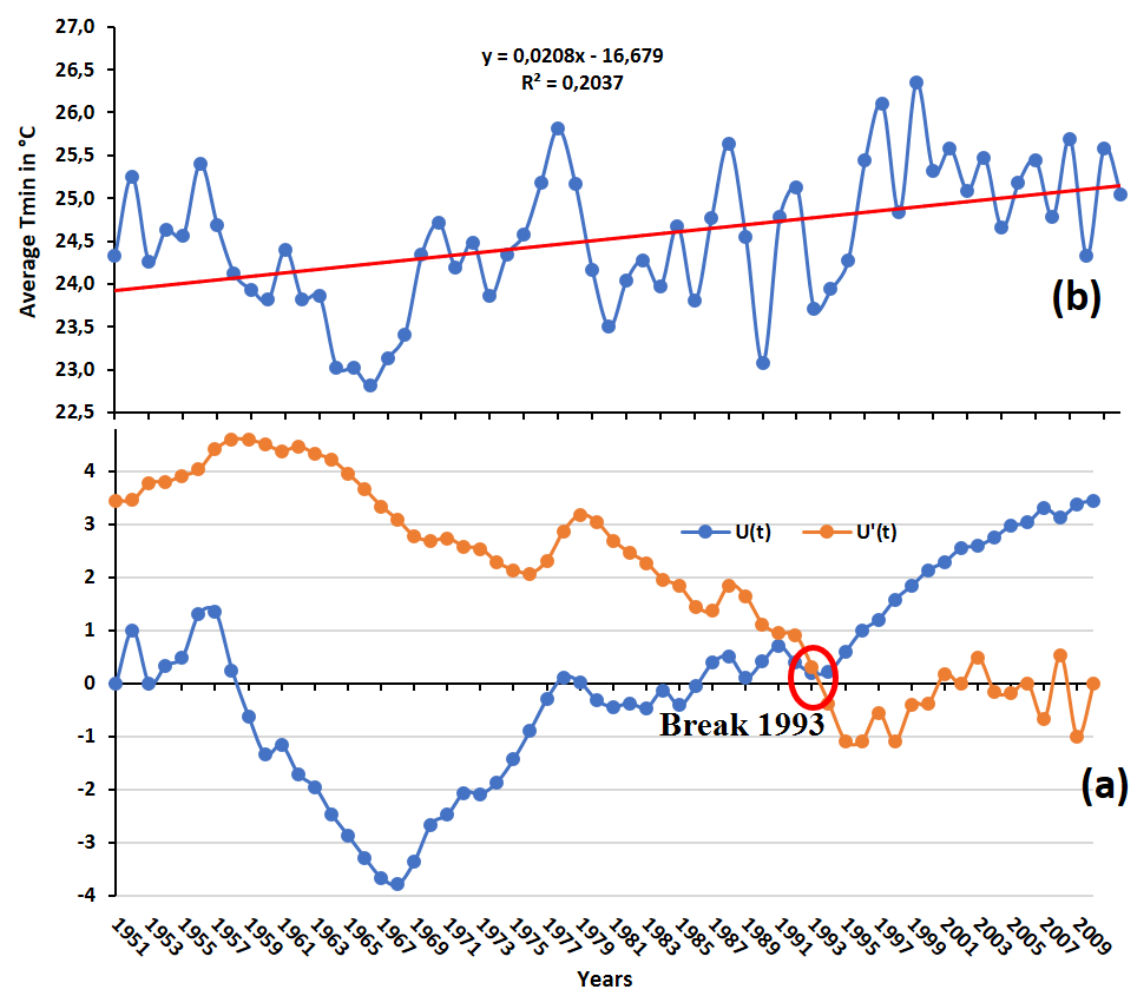

Fig. 4. The mean annual minimum temperature (Tmin) trend averaged over June to September of the Bechar station (1951-2010)

(a) - graphic of the series $u(t)$ and the backward series $u^{\prime}(t)$ of the Mann-Kendall statistic test with significant trends for the study period; (b) - the evolution of the minimum temperature with time 


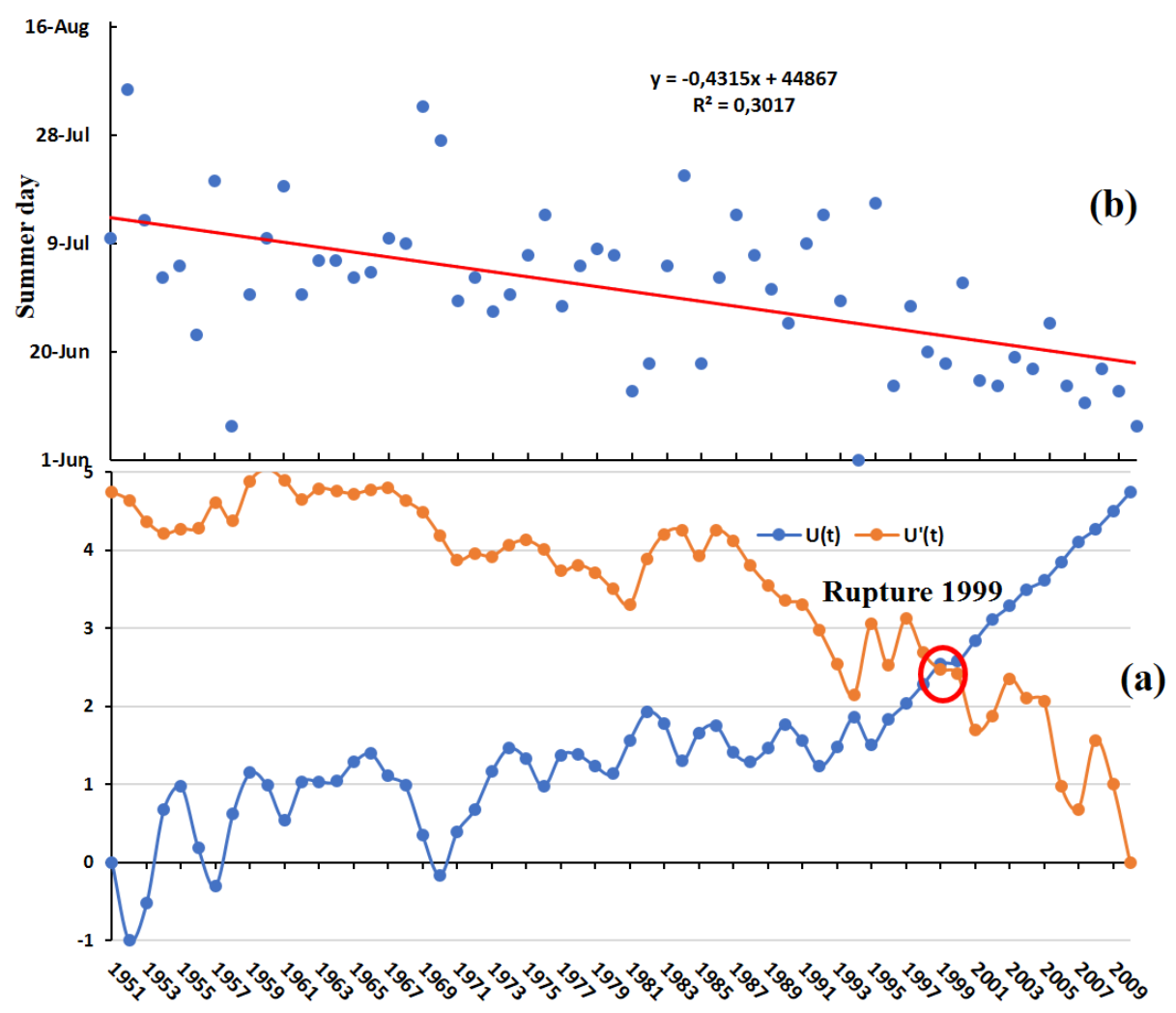

Fig. 5. The temporal trend for the onset of the warm period at Bechar station (1951-2010)

(a) - graphic of the series $u(t)$ and the backward series $u^{\prime}(t)$ of the Mann-Kendall statistic test with significant trends for the study period; (b) - the date of the first extremely hot day in the year

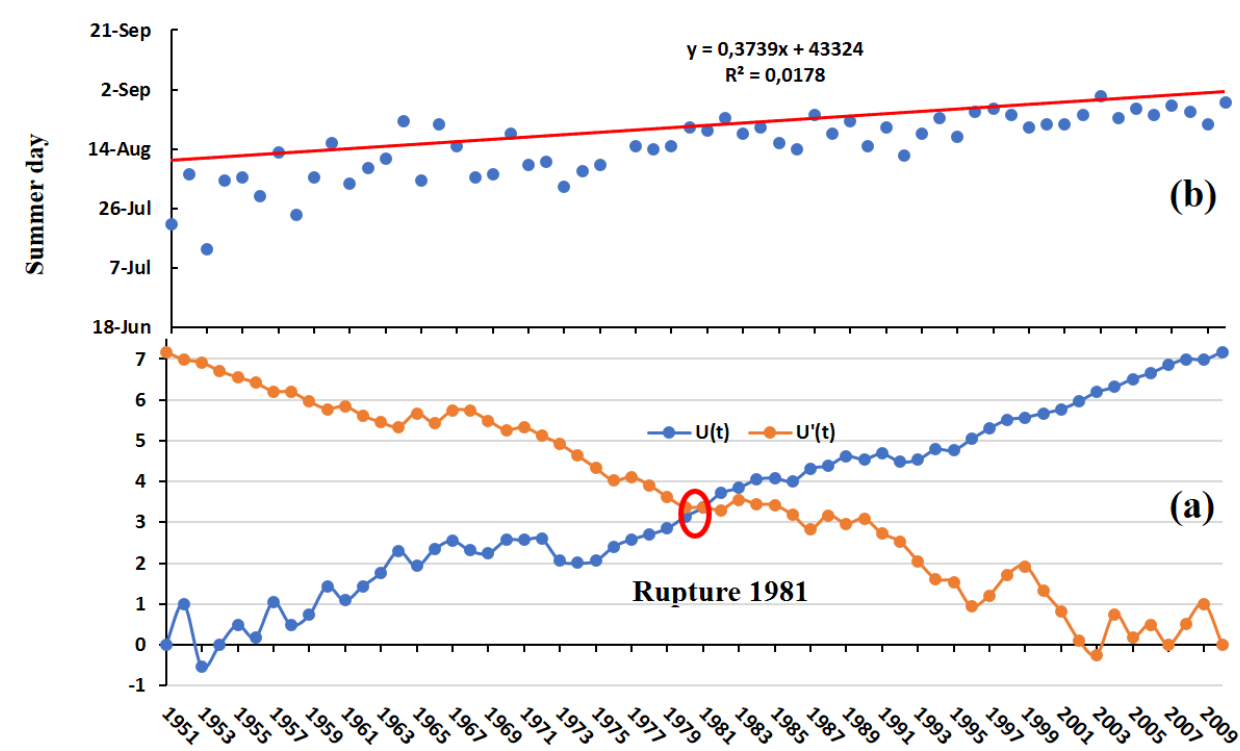

Fig. 6. The temporal trend for the end of the warm period at Bechar station (1951-2010)

(a) - graphic of the series $u(t)$ and the backward series $u^{\prime}(t)$ of the Mann-Kendall statistic test with significant trends for the study period; (b) - the date of the first extremely hot day in the year 


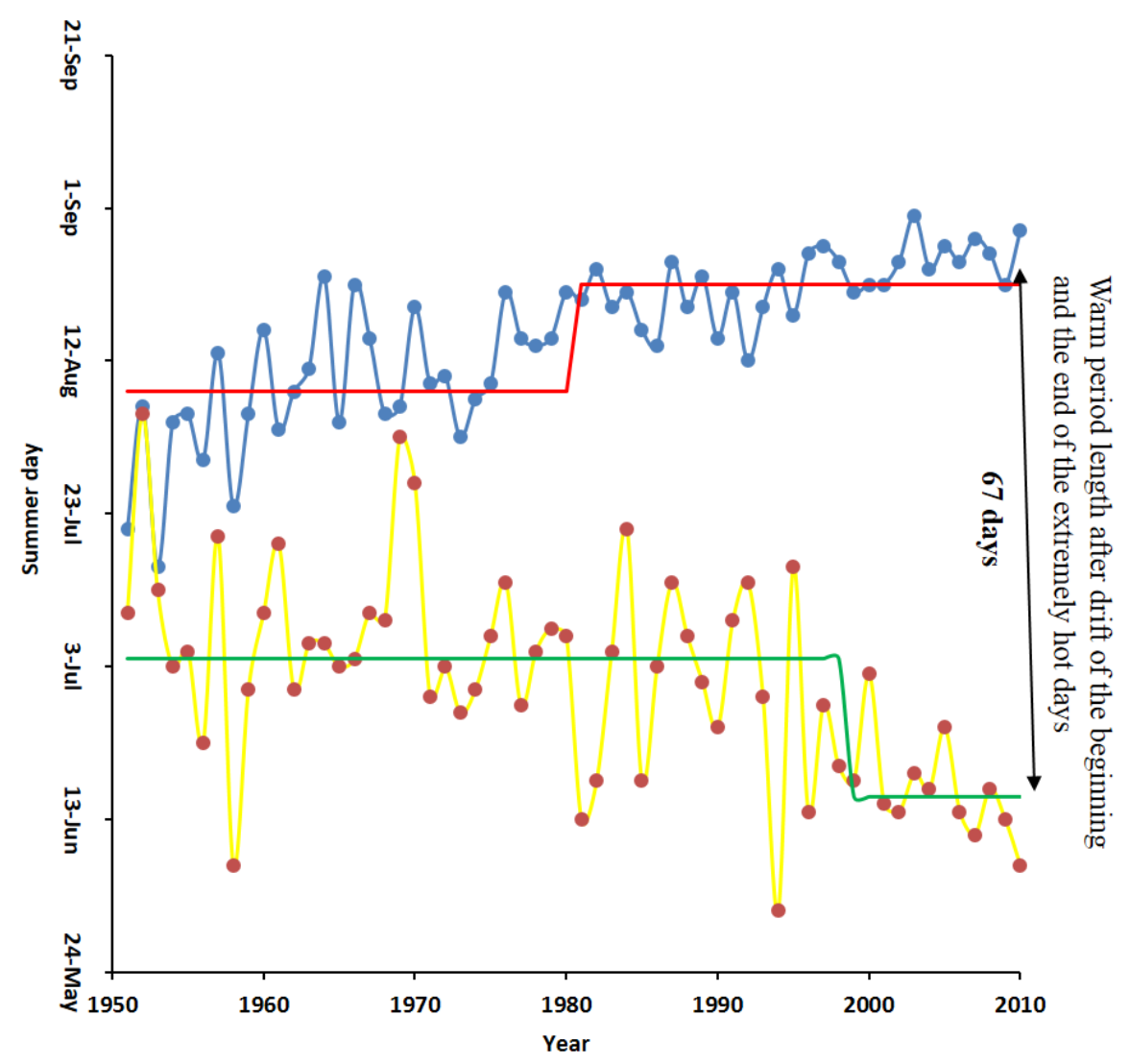

Fig. 7. Illustration of the elongation of the warm period during (1951-2010)

the yellow curve the dates of the first extremely hot days, the blue curve represents the dates of the last extremely hot days for each year of the study period; the green line represents the average date of the first extremely hot days occurrence before and after the drift of the onset, the red line represents the average date of the last extremely hot days occurrence before and after the drift of the end

\section{Discussion}

The temperature increase calculated regarding the identified rupture is $1{ }^{\circ} \mathrm{C}$ in maximum temperature and $0.9^{\circ} \mathrm{C}$ in minimum temperature. The results are in line with various studies. The experts of the Berkeley Earth Organization (Rohde et al. 2013) showed a clear increasing tendency in the average temperature of Bechar station during the period 1951-2010. Experts from the National Meteorological Office (NOM 2004) drew the same conclusions. They noticed an increase in temperature during all the seasons ranging from 0.8 to $1^{\circ} \mathrm{C}$. Almazroui et al. (2020) confirmed that, under the intense forcing SSP5-8.5 scenario, the most significant rise in mean annual temperature $\left(5.6^{\circ} \mathrm{C}\right)$ is projected over the Sahara by the end of the twentyfirst century.

The temperature variation in summer is consistent with extreme heat events that have occurred more frequently in summers (Sheridan, Lee 2018).
The expansion in the warm period calculated regarding the identified breaks is 18 days attributed to the earlier appearance of the first extremely hot day and 14 days attributed to delay of the last extremely hot day. These results agree with the conclusions of previous works. Since the 1950s, in the extended summer season, from May to September in the northern hemisphere, the high heat sequences have become longer and more frequent, in line with global warming (Faci et al. 2016, 2018; Perkins-Kirkpatrick et al. 2020; Driouech et al. 2020). These results confirm that our climate is warming nationally and at the regional level.

\section{Conclusions}

The analysis of the temperature data of the meteorological station of Bechar permitted us to detect significant changes that occurred in this region, which is typically known as very hot, and where the tendency towards extreme warming is clear. 
The breaks in the annual summer temperature records caused an average increase of $1{ }^{\circ} \mathrm{C}$ in the maximum temperature after 1994 and $0.9^{\circ} \mathrm{C}$ in the minimum temperature after 1993.

To study the possibility of warm period extension, we took into account the daily maximum and minimum temperatures data of the warm season (June to September) during the period 1951-2010; we applied the Mann-Kendall test on the dates of the extremely hot days. The analysis revealed significant changes in both the onset and the end of the warm period. These changes are attributed to the early onset of the first extremely hot days and the delayed end of the last extremely hot days. A significant shift was found in both the early onset of the first extremely hot days and the late occurrence of the last extremely hot days of about two weeks during the study period. The progressive and retrograde test of Mann-Kendall shows that the break points appeared in, respectively, 1999 and 1984 for the onset and the end of the extremely hot days. These trends caused an expansion of more than 30 days in the length of the warm period.

\section{Acknowledgments}

The authors are grateful to the anonymous reviewers for their helpful comments.

\section{References}

Allstadt A.J., Vavrus S.J., Heglund P.J., Pidgeon A.M., Thogmartin W.E., Radeloff V.C. 2015. Spring plant phenology and false springs in the conterminous US during the 21 st century. Environmental Research Letters 10: 104008. https://doi.org/10.1088/1748-9326/10/10/104008.

Almazroui M., Saeed F., Saeed S., Nazrul Islam M., Ismail M., Klutse N.A.B., Siddiqui M.H. 2020. Projected Change in Temperature and Precipitation Over Africa from CMIP6. Earth Systems and Environment 4: 455-475.

Barbier J., Guichard F., Bouniol D., Couvreux F., Roehrig R. 2018. Detection of intraseasonal largescale heat waves: Characteristics and historical trends during the Sahelian Spring. Journal of Climate 31(1): 61\{80. 23, 31, 64, 66, 75, 76, 79, 80, 81, 84, 86, 88, 90, 162, 163.

Basagaña X., Sartini C., Barrera-Gómez J., Dadvand P., Cunillera J., Ostro B., Sunyer J., Medina-Ramón M. 2011. Heat waves and cause-specific mortality at all ages. Epidemiology 22: 765-772. https://doi.org/10.1097/EDE.0b013e31823031c5.

Batté L., Ardilouze C., Batté L., Ardilouze C., Déqué M. 2018. Forecasting West African heat waves at subseasonal and seasonal time scales. Monthly Weather Review 146(3): 889-907. https://doi.org/10.1175/MWR-D-17-0211.1.

Boudiaf B., Dabanli I., Boutaghane H., Şen Z. 2020. Temperature and Precipitation Risk Assessment Under Climate Change Effect in Northeast Algeria. Earth Systems and Environment 4: 1-14.

Christidis N., Stott P.A., Brown S., Karoly D.J., Caesar J. 2007. Human contribution to the lengthening of the growing season during 1950-99. Journal of Climate 20: 5441-5454. https://doi.org/10.1175/2007JCLI1568.1.

Driouech F., ElRhaz K., Moufouma-Okia W., Arjdal K., Balhane S. 2020. Assessing Future Changes of Climate Extreme Events in the CORDEXMENA Region Using Regional Climate Model ALADIN-Climate. Earth Systems and Environment 4 : 477-492.

Faci M., Matari A., Oubadi M., Boudjemline F., Farhi Y. 2016. Analyse des journées de forte chaleur à l'Ouest Algérien. JARA, Numéro spécial Canicule 2016: 21-27.

Faci M., Oubadi M., Matari A., Farhi Y. 2018. Heat waves in Algeria: A potential risk. International Journal of Innovative Technical and Applied Sciences 2: 013-021.

Fischer E.M., Schär C. 2009. Future changes in daily summer temperature variability: driving processes and role for temperature extremes. Climate Dynamics 33(7-8): 917. https://doi.org/10.1007/s00382-008-0473-8.

Hoegh-Guldberg O., Jacob D., Taylor M. 2019. The human imperative of stabilizing global climate change at $1.5^{\circ} \mathrm{C}$. Science 365 , eaaw6974. https://doi.org/10.1126/science.aaw6974.

Karl T.R., Nicholls N., Ghazi A. 1999. CLIVAR/GCOS/WMO Workshop on Indices and Indicators for Climate Extremes Workshop Summary. In: T.R. Karl, N. Nicholls, A. Ghazi (eds) Weather and Climate Extremes. Springer, Dordrecht. https://doi.org/10.1007/978-94-015-9265-9_2.

Kendall M. 1975. Rank Correlation Methods, $4^{\text {th }}$ ed. Charles Griffin, London.

Mann H.B. 1945. Nonparametric tests against trend. Econometrica 1(3): 245-259. https://doi.org/10.2307/1907187.

Mazdiyasni O., AghaKouchak A., Davis S.J., Madadgar S., Mehran A., Ragno E., Sadegh M., Sengupta A., Ghosh S., Dhanya C. 2017. Increasing probability of mortality during Indian heatwaves. Science advances 3: e1700066. https://doi.org/10.1126/sciadv.1700066.

Meddi M., Meddi H., Ketrouci K., Matari A. 2005. Tendance du régime pluviométrique et sècheresse dans le nord-ouest algérien. In: IVe colloque du département de géographie. Eau et Espace ressources, enjeux et aménagements.

NMO 2004. National Office of Meteorology. Projection climatique en Algérie à l'horizon 2020. 
NMO 2010. National Office of Meteorology. Annual summary of the weather in Algeria. Algiers.

Oueslati B., Pohl B., Moron V., Rome S., Janicot S. 2017. Characterization of heat waves in the Sahel and associated physical mechanisms. Journal of Climate 30: 3095-3115. https://doi.org/10.1175/JCLI-D-16-0432.1.

Oubadi M., Hamou A., Faci M., Farhi Y. 2020. Impacts des canicules sur les contraintes environnementales dans la région de Béchar. Journal Algérien des Régions Arides 14: 80-101.

Park B.J., Kim Y.H., Min S.K., Lim E.P. 2018. Anthropogenic and natural contributions to the lengthening of the summer season in the northern hemisphere. Journal of Climate 31(17): 6803-6819. https://doi.org/10.1175/JCLI-D-17-0643.1.

Paturel J.E., Servat E. 1996. Procédure d'identification de ruptures dans les séries hydrologiques; modification du régime pluviométrique en Afrique de l'Ouest non sahélienne. IAHS Publication 238: 99-110.

Perkins-Kirkpatrick S.E., Lewis S.C. 2020. Increasing trends in regional heatwaves. Nature Communications 11: 1-8. https://doi.org/10.1038/s41467-020-16970-7.

Peña-Ortiz C., Barriopedro D., Garcia-Herrera R. 2015. Multidecadal variability of the summer length in Europe. Journal of Climate 28(13): 5375-5388. https://doi.org/10.1175/JCLI-D-14-00429.1.

Raei E., MNikoo M.R., AghaKouchak A., Mazdiyasni O., Sadegh M. 2018. GHWR, a multi-method global heatwave, and warm-spell record and toolbox. Scientific Data 5: 180206. https://doi.org/10.1038/sdata.2018.206.

Rohde R., Muller R.A., Jacobsen R., Muller E., Perlmutter S., Rosenfeld A., Wickham C. 2013. A New Estimate of the Average Earth Surface Land Temperature Spanning 1753 to 2011. Geoinfor Geostat: An Overview 1: 1. of, 7, 2. https://doi.org/10.4172/23274581.1000103.
Russo S., Marchese A.F., Sillmann J., Immé G. 2016. When will unusual heat waves become normal in a warming Africa? Environmental Research Letters 11,5: 054016. https://doi.org/10.1088/1748-9326/11/5/054016.

Schwartz M.D., Ahas R., Aasa A. 2006. Onset of spring starting earlier across the Northern Hemisphere. Global Change Biology 12(2): 343-351. https://doi.org/10.1111/j.1365-2486.2005.01097.x.

Santer B.D., Po-Chedley S., Zelinka M.D., Cvijanovic I., Bonfils C., Durack P.J., Zou C.Z. 2018. Human influence on the seasonal cycle of tropospheric temperature. Science 361: eaas8806. https://doi.org/10.1126/science.aas8806.

Sheridan S.C. Lee C.C. 2018. Temporal trends in absolute and relative extreme temperature events across North America. Journal of Geophysical Research: Atmospheres 123: 11889-11898. https://doi.org/10.1029/2018JD029150.

Sneyers R. 1975. Sur L'analyse Statistique des Séries Observations: Note Technique N. 143. Secrétariat de l'Organisations Météorologique Mondiale.

Some'e B.S., Ezani A., Tabari H. 2012. Spatiotemporal trends and change point of precipitation in Iran. Atmospheric research 113: 1-12. https://doi.org/10.1016/j.atmosres.2012.04.016.

Wang J., Guan Y., Wu L., Guan X., Cai W., Huang J., ..., Zhang B. 2021. Changing lengths of the Four Seasons by global warming. Geophysical Research Letters 48(6): e2020GL091753. https://doi.org/10.1029/2020GL091753. 